\title{
CERTIFICAÇÃO DOCENTE E FORMAÇÃO DO EDUCADOR: REGULAÇÃO E DESPROFISSIONALIZAÇÃO
}

\author{
Helena Costa Lopes de Freitas*
}

\begin{abstract}
A formação de professores é um desafio que tem a ver com o futuro da educação básica, esta por sua vez, intimamente vinculada com o futuro de nosso povo e a formação de nossas crianças, jovens e adultos. No entanto, as perspectivas de que essa formação se faça em bases teoricamente sólidas, e fundada nos princípios de uma formação de qualidade e relevância social, são cada vez mais remotas, se não conseguirmos reverter o rumo das políticas educacionais implementadas (...). (ANFOPE, 2002)
\end{abstract}

RE SU M 0 : Este texto analisa as iniciativas do atual Governo Lula no campo da formação de professores. Para esta análise foi considerado 0 Programa Toda Criança A prendendo, orientador da política de formação continuada e da certificação de professores, que oferece as diretrizes para a criação das matrizes de competência e da Rede Nacional de Centros de Pesquisa e D esenvolvimento da Educação. Tais matrizes deverão constituir-se em referência não apenas para os processos de certificação dos professores, mas sobretudo para a acreditação e autorização das instituições formadoras. A atual política, ao dar seqüência às políticas anteriores marcadas pela subordinação do país às agências internacionais de financiamento, indica, portanto, uma continuidade do processo de desprofissionalização do magistério e 0 aprofundamento do processo de controle e regulação do trabalho docente, principalmente por meio dos exames de certificação e da ampliação do caráter tutorial da formação, com a criação da Rede e, nela, a priorização de produção de programas de educação a distância e material didático para a formação continuada de professores da educação básica.

Palavras-chave: Avaliação de professores. Certificação. Formação de professores. Políticas educacionais.

* $\quad$ Professora da Faculdade de Educação da Universidade Estadual de Campinas (Unicamp) e secretária da Associação Nacional pela Formação dos Profissionais da Educação (ANFOPE). E-mail: helena@ unicamp.br

E duc. Soc., Campinas, vol. 24, n. 85, p. 1095-1124, dezembro 2003

Disponível em <http:/ / www.cedes.unicamp.br> 


\title{
TEACHING CERTIFICATION AND PROFESSIONAL TRAINING: REGULATION AND DEPROFESSIONALIZATION
}

\begin{abstract}
A BSTRA CT : The purpose of this work is to analyze the initiatives of Lula Administration related to the professional training of teachers. The analysis was based on the so-called 'Every Child Must Learn' program (Toda Crianca A prendendo), which regulates the ongoing training and certification of teachers and sets the guidelines to establish competency standards and a National Network of Educational Research and D evelopment Centers. The referred standards should be established with reference to not only the teachers' certification procedures but also to the official recognition and authorization of professional training institutions. The current policy is in line with former policies marked by subordination to international financial agencies, and, therefore, represents the continuity of the deprofessionalization of teacher training. It also implies the increased control and regulation of teaching activities, mainly by means of certification exams and the increasingly tutorial nature of training as a result of the referred Network and, with it, the prioritization of distance learning programs and teaching material for the ongoing training of basic education teachers.

Key words: Evaluation of teachers. Certification. Teacher training. Educational policies.
\end{abstract}

\section{Relembrando alguns pontos de partida}

$\mathcal{E}$ m artigos anteriores (Freitas, 1999 e 2002) tratamos das concepções teóricas que marcaram as décadas de 1980 e 1990, no processo de democratização da escola e da formação dos educadores. A reação ao pensamento tecnicista das décadas de 1960 e 1970, que marcou os anos de 1980, foi superada, nos anos de 1990, contraditoriamente, pela centralidade no conteúdo da escola (habilidades e competências escolares), fazendo com que fossem perdidas dimensões importantes que estiveram presentes no debate dos anos 80. A ênfase ex cessiva do que acontece na sala de aula, em detrimento da escola como um todo (Freitas, 2000), o abandono da categoria trabalho pelas categorias da prática, prática reflex iva, nos estudos teóricos de análise do processo de trabalho, terminou por centrar a ação educativa na figura do professor e da sala de aula, na presente forma histórica, dando margem para a definição de políticas educacionais baseadas exclusivamente na qualidade da instrução e do conteúdo. As mudanças curriculares, os PCNS, e principalmente a avaliação, constituem-se nestes instrumentos que objetivam impor, à educação e à escola, a 
lógica restrita da produção e do desenvolvimento da laboralidade aos processos de formação, em uma perspectiva produtivista e unidimensional (Frigotto, 1996), em detrimento da formação humana multilateral (Freitas, 2000).

Nos anos de 1990, a "década da educação", vivenciamos o aprofundamento das políticas neoliberais. 0 processo de ajuste estrutural, com 0 enxugamento dos recursos do Estado para a educação e para as políticas sociais, e a privatização criam novas formas de direcionamento dos recursos públicos: sua distribuição, centralização e focalização para as experiências que se adeqüem aos princípios das reformas sociais em curso. Configura-se o descompromisso do Estado para com o financiamento da educação para todos, em todos os níveis, revelando a subordinação do nosso país às exigências do Banco Mundial e à lógica do mercado.

No âmbito das políticas de formação de professores mudanças significativas foram implementadas, objetivando a construção de um professor com habilidades e competências capazes de torná-lo a correia de transmissão, na escola e na sala de aula, das novas formas de laboralidade demandadas pelo nível de desenvolvimento do capitalismo na atualidade.

Como se configuram as políticas de formação neste novo governo, diante desse quadro? Conseguem romper com esta lógica? Este é 0 objeto do presente artigo.

\section{I - As políticas de formação: profissionalização ou flexibilização?}

No campo da formação dos profissionais da educação, estamos vivenciando o que poderíamos configurar como o retorno às concepções tecnicistas e pragmatistas da década de 1970, agora em um patamar mais avançado, deslocando o referencial da qualificação do emprego - qualificação profissional - para a qualificação do indivíduo (Kuenzer, 2003, p. 22) - em que a concepção neoliberal de competência tem levado a centrar os processos de formação no desenvolvimento de competências comportamentais. As D iretrizes Curriculares para Formação de Professores para a Educação Básica (CNE, 2002) materializam esta concepção do ponto de vista da organização institucional e da estrutura curricular.

A definição das linhas mestras da política de formação de professores, o Programa Toda Criança Aprendendo e seus desdobramen- 
tos - a Portaria no $1.403 / 2003$, que definiu o Exame de Certificação de Professores e a Rede Nacional de Centros de Pesquisa e D esenvolvimento da Educação, constituída no âmbito do Sistema Nacional de Certificação e Formação Continuada de Professores dos Programas e criada pelo Edital no 01/ 2003 da SEIF/ MEC, bem como a Minuta de Resolução, em discussão no CNE, que dá organicidade à legislação existente sobre formação de professores e institui transformações polêmicas no âmbito da pedagogia - , configuram este novo quadro que, como um mata-borrão, vai imprimindo desenhos desfigurados da matriz que lhe deu a cor.

Tal reconfiguração, entretanto, mantém o caráter e a concepção presentes nas políticas de formação formuladas e implementadas no governo anterior.

Em artigos anteriores, desenvolvemos a análise de que há um movimento aparentemente contraditório de profissionalização, regulação e flexibilização do trabalho docente, revelado, a partir da aprovação da LDB, pelas seguintes proposições em desenvolvimento nesse período:

a) manutenção da formação de professores para educação infantil e séries iniciais do ensino fundamental, em nível médio;

b) flexibilização no exercício do trabalho docente, ao instituir a possibilidade de formação pedagógica para qualquer bacharel proveniente das demais áreas e profissões - Resolução no 02/ 97 - , legitimando o magistério como "bico" e flexibilizando, portanto, também a formação, pela complementação pedagógica;

c) recuperação da concepção de "formação em serviço", que teve grande vigor na década de 1960, e de "aproveitamento de estudos", como fundamentos da formação do profissional da educação, trazendo para o âmbito da legislação a ênfase na experiência e nas práticas como elemento definidor da qualidade da formação, restringindo a importância da sólida formação teórica e epistemológica no campo da educação ${ }^{1}$ e imprimindo a visão dicotômica da relação teoria e prática;

d) institucionalização dos Institutos Superiores de Educação (ISES) como espaço preferencial para a formação de professores, in- 
clusive em nível de pós-graduação, tal como preconizado pela Minuta de Resolução em discussão no CNE desde julho de $2002 ;^{2}$

e) regulamentação da certificação de professores como mecanismo de avaliação e premiação dos professores, processo do qual poderão participar também os professores leigos, reforçando a noção de competência individual para determinadas tarefas e não para 0 trabalho, entendido como totalidade rica de múltiplas e complex as relações;

f) retirada dos atuais cursos de licenciatura do âmbito da educação e do lócus específico de produção de conhecimento no campo da educação e da pedagogia: as faculdades e os centros de educação nas universidades.

Este movimento das políticas é parte de um movimento maior, no campo das idéias, que vem influenciando os estudos da área desde início da década de 1990 (Oliveira, 2000; André, 2000), com a implementação das reformas educativas nos diferentes países. A explicitação das políticas e das concepções que as informam é uma necessidade que está posta na atualidade e que nos movimenta como estudiosos da temática.

Nesta perspectiva, este artigo trata de alguns dos principais pontos aprovados na Conferência Regional "O desempenho dos professores da América Latina e Caribe: novas prioridades", realizada ainda sob 0 anterior governo, no período de 10 a 12 de julho de 2002, em Brasilia, com a participação dos representantes dos Ministérios da Educação de Argentina, Brasil, Chile, El Salvador, México, Nicarágua, Paraguai, Uruguai e Suriname (MEC/ INEP/ BID, 2002). Partindo do reconhecimento de que a formação e capacitação docente têm importância central para garantir uma educação de qualidade para todos na A mérica L atina e no $\mathrm{C}$ aribe e a premência da valorização da profissão docente por meio do estabelecimento de condiçoes dignas de trabalho para um melhor desempenho profissional, o documento final da Conferência indica 14 recomendações estratégicas que seriam submetidas aos respectivos governos dos países ali representados.

Essas recomendações tomam a temática da avaliação de desempenho docente como central para atingir os objetivos de eqüi- 
dade, qualidade e responsabilidade, focalizam os aspectos regulatórios dessas políticas, quais sejam, a acreditação de cursos e certificação/ recertificação de competências docentes, com base em exames teóricos e práticos, enfatizando a ação de professores-tutores nas atividades de desenvolvimento profissional dos professores. A Conferência colocou ênfase na necessidade de utilização das novas tecnologias como recursos de ensino nas escolas de educação básica, apontando para a familiarização dos professores com esses meios de formação como parte de sua própria aprendizagem e desenvolvimento profissional.

Essas recomendações sistematizam e referendam um conjunto de iniciativas que vinham sendo tomadas no governo anterior, entre as quais destacamos a definição das Diretrizes Curriculares Nacionais para a Formação em Nível Superior de Professores para a Educação Básica e a proposta do sistema nacional de certificação de competências docentes.

Anteriormente (Freitas, 1999 e 2000) analisamos as concepções que fundamentam e informam as políticas atuais, evidenciando a subordinação de nosso país aos princípios das reformas educativas exigidas pelos organismos internacionais (Warde, Fonseca \& Torres, 1996). Identificamos as referências e as bases para as políticas de formação de professores que desde a década de 1990 vêm sendo implementadas em nosso país, com o objetivo de adequar a formação de professores e a educação básica às exigências postas pelas modificações no âmbito do trabalho produtivo para o desenvolvimento do capitalismo. Neste quadro, a formação de professores ganha relevância por sua dimensão estratégica na formação das novas gerações. As concepções que informam estas proposições se confrontam nos espaços de definição das políticas, e é necessário que possamos resistir à lógica de traçar os rumos da formação de professores a fim de fazê-los possuidores de determinadas competências para "aterrizar" a reforma educativa na sala de aula. Indicar, ao mesmo tempo, uma política global de formação e profissionalização dos educadores e as mudanças na forma de organização da escola atual, este é o nosso desafio.

Q uais as rupturas necessárias para enfrentar esse desafio? Esta é a questão central que nos orienta neste artigo 


\title{
A nova configuração da formação: a política desvirtuada
}

\begin{abstract}
Que a formação docente para a educação básica se dê em instituições especificamente voltadas para esse fim, preferencialmente no nível pós-secundário. Aos professores em exercício na educação básica que não tenham estudos superiores, deverá ser dada oportunidade de realizá-los, garantindo melhor domínio dos conteúdos a serem lecionados e constituição de competências pedagógicas para promover a aprendizagem dos mesmos. (Conferência regional, item 4, grifos nossos)
\end{abstract}

A criação, na LDB, de novas instâncias e cursos de formação, como os Institutos Superiores de Educação (ISES) e o curso normal superior (Art. 63), atendeu ao objetivo de diversificação das Instituições de Ensino Superior (IES) imposto pelos organismos financiadores ${ }^{3}$ internacionais aos diferentes países, visando a reduzir os altos custos com a formação desenvolvida em instituições universitárias com investigação e pesquisa, a partilhar a ampliação da oferta de ensino superior com instituições privadas e a tornar mais ágil, prática e eficiente a formação dos quadros do magistério (Freitas, 1999; 2002), condições necessárias para "aterrizar a reforma na sala de aula", em outras palavras, a formação superior mas não necessariamente universitária pós-secundária - , como recomendada no documento acima referido.

A construção desta política, bem como sua regulamentação nos últimos 10 anos, vem se dando por meio da ampliação desenfreada do ensino superior privado, ${ }^{4}$ principalmente dos cursos de formação de professores para a educação básica - por meio da expansão e institucionalização dos ISEs e cursos normais superiores como instâncias privilegiadas de formação de professores.

Ao mesmo tempo, vivenciamos nas IEs públicas um processo de intensificação do trabalho e da ênfase no produtivismo docente, conseqüência da redução do quadro de professores, da crescente pauperização das universidades públicas e do processo de avaliação implementado nos últimos anos na graduação - o Provão - , mas principalmente na pós-graduação, e a impossibilidade de ampliação significativa do número de vagas que possa fazer face às crescentes demandas dos jovens pelo ensino superior. Criam-se, neste quadro, as condições objetivas para 0 financiamento de bolsas a estudantes das instituições privadas, 
como vem sendo implementado pelo governo do estado de São Paulo e política anunciada também pelo governo federal, ${ }^{5}$ consolidando, nas políticas atuais, 0 significado de público na ótica das políticas neoliberais: nem estatal, nem gratuito. Estas medidas são prenúncio para a cobrança de mensalidades nas instituições públicas, tal como recomendado pelo Banco Mundial, incorporada em recente documento do Ministério da Fazenda. ${ }^{6}$

Vão se firmando, portanto, neste quadro, três movimentos:

a) uma política de consolidação dos Institutos Superiores de Educação como lócus exclusivo e privilegiado de formação de professores para toda a educação básica - graduação e pós-graduação - ,7 com uma concepção de formação pós-secundária;

b) retirar a formação de professores do campo da educação, pelo afastamento das atuais faculdades de educação da responsabilidade pela formação desses profissionais, ${ }^{8}$ deslocando-a para o campo da epistemologia da prática, a ser desenvolvida nos ISES, em toda sua plenitude, na concepção da formação técnico-profissional;

c) a prevalência de uma concepção pragmatista de formação de professores, em curso também nas nossas universidades, em decorrência de um movimento de idéias no campo da educação, que vem abraçando desde o início da década de 1990 as idéias oriundas das concepções das reformas educativas nos diferentes países (Freitas, 2002), fundadas na epistemologia da prática (Tardif, 1998) e na lógica das competências.

A Minuta de Resolução em discussão no $\mathrm{CNE}^{9}{ }^{9}$ tratando da Formação dos Professores da Educação Básica é a expressão legal destes movimentos.

A proposta definida pelo documento abre a possibilidade de que, nos Institutos Superiores de Educação, possam existir também, além do curso normal superior, cursos de pedagogia, com licenciaturas para a educação infantil e para as séries iniciais do ensino fundamental. A carga horária e o conteúdo dessa pedagogia com licenciatura seguem o conteúdo curricular do curso normal superior - 2.800 horas, em 3 anos, definida pelas Diretrizes Curriculares Nacionais para a Formação em 
Nível Superior de Professores para a Educação Básica, aprovadas em maio de 2002. Para a formação dos especialistas, nos moldes propostos pelo Art. 64 da LDB, cria-se uma nova figura de curso - o bacharelado em pedagogia - , a ser regulamentado por diretrizes curriculares próprias. A pedagogia-licenciatura poderá ser complementada pelo bacharelado em pedagogia, com carga horária de 800 horas.

A minuta propõe ainda a criação de cursos de pós-graduação, em nível de mestrado, doutorado e especialização, nos termos da legislação vigente e ainda a pós-graduação profissional.

Todo o esforço desde 1997, desenvolvido pelas entidades da área - ANFOPE, ANPED, ANPAE e FORUMDIR -, vem sendo no sentido de tratar as Diretrizes para o Curso de Pedagogia, no âmbito da formação dos profissionais da educação - envolvendo todas os cursos de formação de profissionais da educação: as atuais licenciaturas e o curso de pedagogia, na tentativa de superar a dicotomia atualmente existente entre licenciatura - formação de professores - e bacharelado formação dos educadores/ cientistas da educação.

É essa dicotomia que o documento retoma neste momento, mas o faz de uma maneira contraditoriamente sutil e agressiva, demonstrando uma "flexão tática" ao possibilitar às IEs transformar os atuais cursos normais superiores nas licenciaturas em cursos de pedagogia, com o objetivo de "apaziguar os ânimos", e resolver, via legislação, a crise de inadimplência e esvaziamento dos Cursos Normais Superiores hoje existentes. Esta proposição revela a face perversa da atual política de regulamentação dos Institutos Superiores de Educação, criados pela LDB, como já foi apontada em inúmeros estudos nos últimos 8 anos.

As conseqüências para o campo das ciências da educação e da pedagogia deverão ser examinadas pelos estudiosos da área a partir de seus impactos na educação básica e das suas manifestações na concepção de formação de nossa infância e juventude.

Cumpre-se, efetivamente, um novo ciclo da $2^{\mathrm{a}}$ fase da reforma educativa (Freitas, 2002), que atinge o campo da formação de professores, com suas implicações:

1. Retirar a formação de professores do campo da educação, retirando-a das faculdades/ centros de educação e deslocandoa para o campo da epistemologia da prática, a ser desenvol- 
vida nos ISES, em toda sua plenitude, na concepção da formação técnico-profissional. Às faculdades/ centros de educação, que poderão continuar a formar seus professores - desde que nesses moldes - , será reservado o espaço da "excelência" e da ciência: a formação do educador para outros espaços educativos.

2. D o ponto de vista institucional-administrativo, acentua-se 0 quadro atual, de rebaixamento da formação dos professores: noS ISES, separados da produção de conhecimento nas diferentes áreas - as exigências para criação, autorização e funcionamento continuam as mesmas: $10 \%$ de mestres e doutores e $30 \%$ em tempo integral, ao passo que nas universidades e nos centros este índice aumenta e se busca a excelência com critérios da CAPEs e da pós-graduação.

3. A decisão de criar pós-graduação - nos moldes atuais ou profissionalizantes - nos atuais ISES somente aprofundará as diferenças entre os mestrados acadêmicos e os profissionalizantes, além de deslocar grande parte dos recursos públicos para a pósgraduação e a pesquisa, para as instituições privadas que hoje mantêm os ISES e, neles, Cursos Normais Superiores.

Recente documento do CNE, retirado de pauta na reunião de abril de 2003, discute as propostas de redução do tempo de formação nos cursos de graduação (das quais estariam excluídos os cursos de formação de professores, cuja carga horária já foi aprovada) - para 3 anos, com um complicado jogo de horas/ dias letivos, ampliando significativamente o número de horas do aluno (!) sem assistência dos professores. A essa redução corresponderia a possibilidade de certificação profissional colocada na pós-graduação e não mais na graduação, mediante a atuação dos conselhos e das corporações de ofício. Para os professores, essa medida foi antecipadamente implementada pela SEIF/ MEC mediante a certificação, à qual podem concorrer, voluntariamente, quaisquer professores em ex ercício - leigos inclusive - , e obrigatoriamente os licenciandos.

Esta nova configuração da formação de professores, caso aprovada, trará ainda as seguintes implicações:

1. criação de uma pedagogia escolar para a formação dos profissionais da escola - professores e especialistas - , separada do 
campo das ciências da educação, possibilitando a retomada das habilitações; a expressão "obedecida uma base comum nacional" presente no Art. 64 da LD B é tomada como formação anterior (complementada por) sobre a qual se dá a formação dos especialistas, contrapondo-se à concepção de base comum nacional construída pelo movimento dos educadores e a ANFOPE (ANFOPE, 1992);

2. a formação do especialista (antigas habilitações) para o exercício das funções do magistério transforma-se no conteúdo da formação do bacharelado de pedagogia, ao estabelecer que esse curso formará os especialistas, mediante complementação pós-licenciatura ou integrada, e se orientará pelas diretrizes próprias para os cursos de pedagogia, a serem aprovadas pelo $\mathrm{CNE}$;

3. separação da formação do professor da formação do pedagogo especialista/ bacharel, uma vez que as diretrizes que orientarão a organização da pedagogia-licenciatura serão as mesmas dos cursos normais superiores;

4. a extinção de todos os cursos de pedagogia com outras habilitações, tornando possível que um novo curso abrigue a formação dos educadores para Educação de Jovens e Adultos, educação indígena, educação especial, empresas, MST, movimentos sociais (o conteúdo de inúmeros cursos de pedagogia que hoje formam unitariamente os profissionais da educação), enfim, todas as imensas possibilidades de atuação que já existem e outras que aparecerão, fragmentando ainda mais essas formações, avançando para a concepção de flexibilização curricular, tal como proposta em 1997 pela Resolução no 04/ 97 do CNE que instituiu as Diretrizes Curriculares para todos os cursos de graduação.

Este processo, em curso em nosso país, pretende efetivamente retirar das atuais universidades a formação de professores, proposta que vai ao encontro de estudos desenvolvidos em outros países propondo o abandono da lógica disciplinar com 0 intuito de trabalhar segundo uma lógica profissional centrada no estudo das tarefas e realidades dos trabalhos dos professores "tirando das disciplinas o con- 
trole total na organização dos cursos" (Tardif, 2000), abandonando uma formação de cunho científico-acadêmica.

Duarte (2003) afirma que "mesmo na universidade esta formação poderá não ser assegurada, uma vez que tais concepções propõem uma ampla mudança estrutural nos cursos de formação e nas carreiras universitárias, de modo a relegar a segundo plano os conhecimentos acadêmicos, científicos, teóricos".

Do ponto de vista institucional e acadêmico, a minuta mantém 0 rebaixamento das exigências para autorização e funcionamento de cursos: $10 \%$ de mestres e doutores e 1/ 3 em regime de tempo integral e metade com comprovada experiência na educação básica, ao passo que nas universidades e nos centros se busca a excelência com critérios da CAPES e da pós-graduação e as exigências cada vez maiores de elevar a titulação.

Nossas posições históricas - a luta pela formação do educador de caráter sócio-histórico e a docência como base da formação dos profissionais da educação - têm um caráter avançado: apontam para a necessidade de superação da fragmentação na formação - formar o especialista no professor - como para a superação da dicotomia - formar 0 professor e 0 especialista no educador.

Em inúmeras IES, em determinados momentos históricos da luta pela formação e pela definição de políticas, entendeu-se, de forma parcial, a superação da fragmentação como um passo suficiente, na formação dos professores. Esta é uma discussão que no âmbito da ANFOPE é clara, pois o movimento tem suas origens justamente nessa resistência, quando Valnir Chagas tentou fazer do curso de pedagogia um curso de caráter técnico-profissional para formar professores, jogando as habilitações - que naquele momento histórico e de evolução da área, ainda sem a pós-graduação, tinham outro caráter - para a pós-graduação.

Os embates com colegas da área polemizam justamente sobre este particular, revelando compreensões diferenciadas sobre 0 caráter da ciência pedagógica e a formação dos profissionais da educação. A política de aligeiramento da formação inicial, a ênfase em seu caráter técnico-profissionalizante, rebaixando as exigências no campo teórico e epistemológico, aliadas ao desmantelamento das instituições públicas universitárias e da expansão desqualificada do ensino superior pri- 
vado, vêm produzindo o perverso quadro revelado também pela pesquisa Retrato da Escola, desenvolvida pela CNTE (CNTE, 2002), e pelos dados da educação pública em nosso país, amplamente divulgados pela mídia nos últimos meses. 0 alerta da CNTE de que a política educacional vigente secundariza este aspecto da qualificação profissional, preferindo atuar na capacitação em servico, privilegiando os aspectos técnicos e metodológicos do trabalho, reforça as análises que têm sido feitas por estudiosos em nosso país, no sentido de identificar, na retirada da formação de professores da ambiência universitária, a negação da construção da identidade do professor como intelectual e pesquisador da educação, atributos reservados apenas àqueles que atuam no ensino superior (ANFOPE, 1998, 2000; Kuenzer, 1999).

\title{
Certificação de competências: a real política de formação e instru- mento de avaliação
}

\begin{abstract}
Que as políticas nacionais de formação docente forneçam parâmetros e diretrizes para ações voltadas para o desenvolvimento profissional dos professores e contemplem componentes necessários à qualidade dos cursos e programas educacionais, inclusive relativos a acreditação e certificação, a partir de ex ames teóricos e práticos. (Conferência Regional, 2002, item 3, grifos nossos)
\end{abstract}

Uma das características essenciais no quadro que se desenhou a partir da redefinição do papel do Estado, originário das mudanças ocorridas no âmbito do capitalismo, é a necessidade de regulação, que adquire caráter central no campo da educação e da formação de professores. É este caráter do Estado, regulador, que orienta as diferentes políticas e suas medidas de implementação, buscando responder a questões como: quais os conhecimentos necessários a todas as crianças e jovens (PCNS), como desenvolver a aprendizagem desses conhecimentos (diretrizes e referenciais), como preparar os professores (competências necessárias) para essa tarefa, quais as instituicōes mais adequadas e sua forma institucional e pedagógica (regulamentacão doS ISEs) e, por último, como avaliar as diferentes instâncias e sujeitos envolvidos nas tarefas educativas postas pela reforma (sistemas de avaliação de estudantes - SA EB, E N E M e Provão) e como controlar 0 trabalho docente e a produção da formação - os atuais processos de certificação de professores e acreditação de cursos e instituiçoes. 
Em artigos anteriores (Freitas, 1999 e 2002) analisamos o movimento de produção das diretrizes de formação, tanto pelo MEC quanto pelas entidades científicas e acadêmicas da área, e ainda como a lógica das competências foi incorporada a esses documentos, com base na produção da área educacional na década de 1990, que dirigiu seu olhar para os estudos que se desenvolviam em outros países, notadamente aqueles nos quais a reforma educativa vinha produzindo novos paradigmas para a formação de professores, situando a investigação sobre formação de professores no campo de uma epistemologia da prática. D entre esses estudos, podemos citar os de Schön, Nóvoa, Zeichner, Gaultier, Tardif e Perrenoud, entre outros, de forte cunho pragmatista e escolanovista (D uarte, 2003).

Analisamos como esta aproximação com o trabalho, reduzido à prática individual, é desenvolvida na atualidade, do ponto de vista perverso do capital, manifesta na redução da formação ao caráter técnico-profissionalizante, ${ }^{10}$ ao conceito de competitividade e à avaliação, visando à adequação da educação e da escola às transformações no âmbito do trabalho produtivo.

A concepção de competência, "nuclear na organização dos cursos de formação de professores" (CNE, 2001, p. 28), é incorporada na definição do perfil do novo profissional, com o objetivo central de adequar a formação de professores às exigências legais postas para a educação básica e aos sistemas de avaliação em desenvolvimento (Freitas, 2002).

A regulação atinge ainda os sujeitos do processo educativo em outra dimensão: do trabalho e da realização profissional. A lógica das competências, ao enfatizar a individualização dos processos educativos, a responsabilização individual pelo aprimoramento profissional, produz 0 afastamento dos professores de sua categoria profissional como coletivo e, em conseqüência, de suas organizações. Portanto, "não abre em si nenhuma solidariedade, já que, presumidamente, não pertence como fonte a uma categoria formalizada que, como tal, pode reivindicar direitos para todos os seus membros" (Isambert-Jamati, 1997, p. 107).

As competências, portanto, caracterizadas como um conjunto de habilidades características de cada indivíduo, contrapõem-se, neste sentido, à dimensão conceitual de qualificação profissional e pro- 
fissão, avalizadas pelo diploma e o qual dá força ao conceito de profissão, e

\begin{abstract}
passa[m] a estar no princípio da organização do trabalho, no lugar da qualificação/ profissão. Enquanto o domínio de uma profissão, uma vez adquirido, não pode ser questionado (no máximo pode ser desenvolvido), as competências são apresentadas como propriedades instáveis dentro e fora do exercício do trabalho. Significa dizer que uma gestão fundada na competência encerra a idéia de que um assalariado deve se submeter a uma validação permanente, dando constantemente provas de sua adequacão ao posto, de seu direito a uma promoção ou a uma mobilidade promocional. (Ramos, 2001, p. 194, grifosnossos).
\end{abstract}

A lógica das competências individuais passa a conformar as subjetividades, via formação de professores, e a educação das novas gerações, a fim de inseri-las desde a mais tenra idade na lógica da competitividade, da adaptação individual aos processos sociais e ao desenvolvimento de suas competências para a empregabilidade ou laboralidade.

É este processo de regulação do trabalho, de habilidades, atitudes, modelos didáticos e capacidades dos professores, que vem orientando as diferentes ações no campo da formação.

Tais processos de certificação - por desempenho e por competência - foram implantados em outros países quando, pela redução do papel do Estado no financiamento da educação pública, tornouse inviável a justa remuneração, pelo salário, do trabalho de todos os professores (Morduchowicz, 2002), e vieram acompanhados, nesses países (em especial Chile, Canadá, Austrália), de outras medidas no campo da organização curricular e acadêmica dos processos de formação de professores. Experiências nos EUA, no Canadá, entre outras, mostram que a preocupação com a avaliação de desempenho docente acompanha políticas de financiamento e subvenção a estabelecimentos privados, e maior controle da comunidade ${ }^{11}$ sobre a escola, tal como no Chile (Mizala \& Romaguera, 1999).

Em recente artigo distribuído pela Internet por um grupo de formação de professores, ${ }^{12}$ Fredric Litto, da Escola do Futuro da USP, relata um processo de reforma no estado de Nova York, em 1998, quando o Conselho Estadual de Educação aprovou uma série de medidas visando à melhoria do ensino e da aprendizagem nas escolas públicas do estado. Essas medidas, segundo ele, "tiveram o efeito de eli- 
minar o monopólio das faculdades de educação e o poder corporativista dos sindicatos de professores do Estado" (Litto, 2003, grifo nosso), e permitiram "levar a sério a questão de como os professores são treinados e monitorados durante suas carreiras" (Litto, 2003).

Entre as medidas consideradas positivas pelo autor, identificamos algumas que apresentam razoável similaridade com os processos vivenciados por nós a partir da promulgação da LDB, em 1996, tais como a Resolução no 02/ 97 que trata da formação pedagógica para bacharéis, a retirada da formação de professores das faculdades de educação e, mais recentemente, o processo de certificação de professores proposto pela Secretaria de Educação Infantil e Fundamental (SEIF) do MEC:

1. a eliminação da obrigatoriedade de diploma de licenciatura para exercer a profissão de professor no Estado; qualquer pessoa que possua diploma de graduação em qualquer matéria e que seja aprovada em exames sobre o conteúdo da matéria que pretende lecionar e sobre a teoria educacional pode ser professor;

2. qualquer faculdade de educação, cujos formandos consistentemente (abaixo de 80\%) sejam reprovados em exames de proficiência profissional, será fechada;

3. a certificação de professores, hoje em caráter vitalício, a partir de setembro de 2000 será por apenas cinco anos, podendo ser renovada se o professor se submeter e for aprovado em 175 horas de educação continuada e se obtiver 0 título de mestrado profissionalizante (sem tese) no prazo de dois anos (esta exigência atualmente é de cinco anos) após iniciar sua carreira; agora é mais fácil retirar a certificação de professores "por incompetência, omissão de responsabilidade profissional ou insubordinação". (Litto, 2003)

A proposta enfatiza a utilização das novas tecnologias educacionais e a informática como caminhos para a superação dos problemas da formação de professores, evidenciando o quanto tais idéias ainda permeiam as opiniões leigas que são elevadas à categoria de dogma:

(...) se houvesse no Brasil um aperto similar por parte da sociedade civil, acredito que as nossas faculdades de educação seriam responsabilizadas por 
enfatizarem excessivamente a reflexão em vez dos aspectos pragmáticos da sala de aula, por terem se omitido totalmente, nas últimas décadas, na introdução de tecnologia educacional e, mais recentemente, na informática na preparação de professores do futuro. Seria interessante ver quem daria a mais moderna preparação de docentes daqui em diante: faculdades, sindicatos ou outras organizaçõ̃es não tradicionalmente dedicadas a esta missão. (Litto, 2003)

A adoção do exame de certificação de professores, como única forma de avaliação do desempenho de professores (que efetivamente não é), evidencia o viés regulatório presente nas políticas do atual governo. As críticas ao modelo de premiação por desempenho nos processos de avaliação de professores já vêm sendo enfatizadas por estudiosos da formação de professores, principalmente pelo caráter coletivo, solidário e partilhado de que se reveste o trabalho educativo e pedagógico de formação de nossa infância e juventude. Todo processo de avaliação/ premiação das competências é sempre um processo de caráter exclusivamente individual e competitivo, e, por que não dizer, punitivo e intimidatório (Morduchowicz, 2002).

A concepção de aprimoramento pessoal, processo que tem na emulação seu valor como auto-superação, em processos parceiros e solidários, tal como nos ensinam os princípios da pedagogia progressista socialista (Manacorda, 1972), é substituída pela competitividade que carrega em si a necessidade de superar ao outro, de sobrepor-se, sempre individualmente, às adversidades próprias do trabalho, que adquire marcas singulares sob o capitalismo.

\title{
Certificação e premiação: a centralidade da regulação do trabalho
}

\author{
Não basta certificar \\ E dar medalha ao campeão \\ O professor hoje precisa \\ Lutar por qualificação \\ Uma política salarial \\ De valorização nacional \\ Pra continuar a formação.
}

(Professor Luiz Antonio Norberto, RN)

O Programa Toda Criança Aprendendo, lançado em junho pela Secretaria de Ensino Infantil e Fundamental (SEIF) do MEC, vem se 
transformando no carro-chefe das políticas do atual governo. Inúmeras iniciativas vêm sendo desenvolvidas nacionalmente tendo como objetivo central firmar "pactos" pela educação, pela aprendizagem, pelo letramento, pela alfabetização, ${ }^{13} \mathrm{com}$ ênfase exclusivamente na formação continuada dos professores.

Uma primeira análise desse Programa nos permite identificar algumas das contradições postas para a atual gestão das políticas educacionais. A primeira delas é a manutenção da centralidade da avaliação nas políticas educacionais do atual governo, que vem direcionando a adoção de medidas de impacto, tais como o Exame Nacional de Certificação e a Rede Nacional de Centros de Pesquisa e Desenvolvimento da Educação. Ao fazê-lo, reforçam as concepções equivocadas sobre as causas dos baixos índices de aprovação dos alunos nos exames nacionais, responsabilizando - mais uma vez - exclusivamente os professores pelo sucesso e/ ou fracasso do desempenho dos estudantes da educação básica.

O utra marca das políticas educacionais atuais é a ausência sentida de uma política de formação inicial de professores, por parte do MEC, que rompa com as concepções e premissas postas pelo governo anterior. Toda a regulamentação anterior no âmbito da formação de professores, informada pelas concepções neoliberais das políticas anteriores - criação dos Institutos Superiores de Educação e dos cursos normais superiores e as Diretrizes Curriculares Nacionais para a Formação em Nível Superior de Professores para a Educação Básica -, continua em vigor, nos mesmos moldes e com as mesmas concepções denunciadas pela área nos últimos oito anos.

Cabe destacar que nos últimos anos a discussão da formação de professores se deslocou para $0 \mathrm{CNE}$, permanecendo no âmbito das regulamentações legais, sujeitas, portanto, às pressões dos setores privatistas que, majoritariamente, impõem a lógica mercantil e mercadológica a essas regulamentações. Os processos de "transformação" dos cursos de pedagogia em curso normal superior - Resolução no 133/ 2001 - e agora a proposta de (re)transformação dos cursos normais superiores em cursos de pedagogia representam uma clara intervenção do CNE nas formulações da política científica para a área, submetendo o desenvolvimento científico do campo das ciências da educação e da pedagogia a essa lógica. 
O crescimento vertiginoso e desordenado do setor privado, e a crescente crise de inadimplência e esvaziamento de seus cursos de formação de professores, contrasta com o processo de estagnação das IES públicas, assoladas pela redução dos recursos públicos para manutenção de suas atividades básicas, pela falta de professores, pelos baixos salários, e evidencia as condições restritivas para a definição de uma política de formação de professores voltada para 0 aprimoramento e a melhoria da educação básica e da escola pública.

O utra contradição presente no Programa refere-se às iniciativas que indicam efetivamente mudança de rumo nas atuais condições de organização da escola e do trabalho docente, tais como a ampliação da jornada escolar e a implantação da escola de tempo integral, a instituição do piso salarial nacional e a instituição da jornada integral para os professores, as quais, por serem iniciativas que demandam grande quantidade de recursos públicos, não têm merecido a necessária centralização dos esforços oficiais.

Pela instituição da Bolsa Federal de Incentivo à Formação Continuada, vinculada à aprovação no exame, com a duração de cinco anos, quando novo processo de certificação ocorre, o ministério mantém o nosso país em sintonia com as políticas neoliberais e com os processos de inserção da profissão docente no quadro das profissões de caráter técnico, em que os trabalhadores são constantemente submetidos a processos de certificação de competências para justificar seu posto de trabalho, conforme analisamos anteriormente. 0 certificado de competência poderá ser utilizado pelos gestores das unidades e redes de ensino como critério em processos seletivos, para monitoramento e avaliação de políticas de formação docente, para a promoção na carreira e a concessão de benefícios ao professor em exercício. A gratificação de incentivo ao letramento, destinada aos professores das séries iniciais, será calculada com base nos padrões de desempenho alcançados pelos alunos das séries ou dos ciclos iniciais das unidades escolares. Tais recursos, concedidos às escolas, poderão ser utilizados para remunerar os professores e servidores.

Vinculada a este processo de certificação e formação continuada, institui-se a Rede Nacional de Pesquisa e D esenvolvimento da Educação, criada pelo Edital no 01/ 2003 da SEIF/ MEC, em 11/ 11/ 2003. Essa Rede tem como objetivo desenvolver tecnologia educaci- 
onal e ampliar a oferta de cursos e outros meios de formação de professores. Segundo o edital, o ministério apoiará ações de formação continuada e desenvolvimento de tecnologia educacional exclusivamente destinados à educação infantil e fundamental, priorizando cursos a distância e semipresenciais, incluindo a elaboração de material didático para a formação docente (livros, vídeos, softwares); desenvolvimento de projetos de formação de tutores para esses programas e cursos; desenvolvimento de tecnologia educacional para o ensino fundamental e a gestão de redes e unidades de educação públicas; associação a instituições de ensino superior e outras organizações para a oferta desses programas (as parcerias). Tais centros serão também apoiados para desenvolver produtos e serviços tendo em vista um mercado de natureza eminentemente pública, competindo-lhes construir os mecanismos de comunicação e de negociação com os potenciais usuários. As áreas de pesquisa aplicada a serem apoiadas são as relativas aos conteúdos do ensino de $1 \stackrel{\text { a }}{a} 4^{2}$ a série, tecnologias de gestão e avaliaçã 0 da educação (Toda Criança Aprendendo, 2003).

Reafirmo aqui algumas preocupações ${ }^{14}$ quanto ao Programa e à política de formação nele contida. Particularmente, considero que estas iniciativas - exame, premiação, bolsa de incentivo ao letramento e bolsa federal - situam-se ainda no âmbito das políticas do governo anterior, como podemos observar no documento da Conferência de 2002. Além de não avançar na formação e profissionalização do magistério em nosso país, a idéia de certificação dos professores pode vir a ser, no que diz respeito à avaliação do trabalho docente, profundamente danosa no processo de flexibilização do trabalho e de desprofissionalização dos professores-educadores, reforçando a competitividade e aprofundando, na sociedade, o clima de individualização e responsabilização de cada professor sobre o sucesso e o fracasso dos estudantes. Contribuirá certamente para instalar uma concepção de trabalho docente de caráter meritocrático, para instaurar/ acirrar o clima de "ranqueamento" e competitividade, inibidores do processo de construção de novas alternativas para a formação de nossas crianças, jovens e adultos a partir do trabalho coletivo e solidário, e da gestão democrática em nossas escolas.

Mais grave, imprime uma concepção de desenvolvimento profissional a esses professores - das séries iniciais do ensino fundamental - , para os quais bastariam cursos a distância, orientação de tuto- 
res e acesso a material didático. A proposta de novos "meios de formação", formação de tutores para programas de formação continuada, a distância e semipresencial, e produção de material didático, reduz a perspectiva de aprimoramento e superação profissional aos cursos e o monitoramento do trabalho dos professores, pelos tutores, objetivando alcançar a meta de elevação do porcentual de certificação dos profissionais de educação (inciso iii, p. 6, Edital no 01/ 2003), respondendo a uma das recomendações da Conferência de 2002: "Que todas as iniciativas de formação e capacitação estejam acompanhadas de avaliações rigorosas baseadas na observação dos resultados das mesmas nas práticas docentes em sala de aula" (item 11 das Resoluções da Conferência, grifo nosso). ${ }^{15}$

\section{As matrizes de competência}

A incorporação da lógica das competências à política de formação de professores teve início com o processo de elaboração das Diretrizes Curriculares Nacionais para a Formação em Nível Superior de Professores para a Educação Básica, aprovadas pelo CNE em maio de 2002. As críticas a essa concepção estão presentes em inúmeros estudos da área (Manfredi, 1998; Machado, 1998; Ramos, 2001) e nos documentos das entidades acadêmicas e científicas como ANFOPE, ANPED, FORUMDIR, ANPAE, que vêm denunciando o caráter competitivo e individualizante de que se reveste esta concepção.

As matrizes de competência (MEC/ SEIF, 2003) construídas pela SEIF/ MEC foram aprovadas em um polêmico encontro nacional ${ }^{16}$ onde as entidades puderam manifestar-se apenas ao final dos trabalhos e com severas críticas à proposta do exame de certificação (CNTE, 2003; FNDEP, 2003). Antecedido por encontros estaduais que recomendaram, em sua grande maioria, a discussão aprofundada da política de formação inicial e continuada e não meramente a certificação e suas matrizes de referência, o encontro nacional referendou as matrizes de competência sem qualquer discussão mais ampla com os professores, sistemas de ensino e instituições formadoras.

Tais matrizes situam-se na linha de continuidade das políticas anteriores, respondendo às recomendações da Conferência Regional de 2002, à qual nos referimos no início deste trabalho. É continuidade do processo de definição das competências necessárias para a 
otimização do trabalho docente e caminho para a "regulação" da carreira docente (MEC/ SEIF, 2003, p. 6) e de processos de acreditação e autorização de cursos de formação, a partir do desempenho dos licenciandos no exame de certificação (MEC/ SEIF, 2003, p. 2). Reúnem um conjunto de habilidades/ capacidades/ competências, centradas nos conhecimentos/ conteúdos que as crianças devem aprender e que o professor deve ensinar. Nesta perspectiva restrita, reduzem o processo educativo ao processo de ensino-aprendizagem, à instrução, limitando as enormes possibilidades de formação de nossa infância e nossa juventude para seu desenvolvimento pleno e a produção de uma nova vida.

Seu conteúdo incorpora não apenas a concepção de competência, mas principalmente a de simetria invertida, nucleares nas D iretrizes para Formação de Professores (CNE, 2003, p. 7), que imprimem a elas a lógica instrumental e técnico-profissional que informa as políticas atuais de formação de nossos professores. Constituem-se, portanto, em elemento central na continuidade da política de avaliação que caracterizou o governo anterior.

No conjunto de 50 itens, divididos em matrizes gerais e matrizes específicas, encontramos competências gerais caracterizadas como "O Direito à Educação", dentre as quais se destacam os conhecimentos sobre o caráter institucional, jurídico e legal da educação, como a Constituição, o Estatuto da Criança e do Adolescente, a LD B e as condições da democratização da educação pela via da educação inclusiva. Constam ainda os "saberes pedagógicos", relativos ao saber técnicoinstrumental necessário aos professores no campo da didática, do currículo, da gestão e do material didático. As matrizes gerais abordam, ainda, as habilidades em "linguagens e matemática" e "sociedade, ciência e tecnologia", e no âmbito das referências específicas, os Fundamentos do E nsino e da A prendizagem - alfabetização, leitura e escrita, conhecimento matemático, ambiente e cultura, e vida e natureza. Temos, assim, uma completa taxinomia de objetivos calcados nas habilidades e nos conhecimentos necessários ao professor dos anos iniciais, no que diz respeito à dimensão cognitiva do processo ensino-aprendizagem. O utras dimensões, ainda que façamos um enorme esforço por entendê-las como matrizes de formação, não estão contempladas neste rol de objetivos/ habilidades/ competências, até porque não as acompanha(m) a(s) concepção(ões) que as orientam, com relação à formação, à educação, ao ensino e à escola. 
As diferentes dimensões da formação omnilateral dos educadores, a concepção de formação sócio-histórica em toda a sua plenitude - nos aspectos cognitivo, ético, político, científico, cultural, lúdico e estético -, que há décadas tentamos construir como política de formação, não são tratadas no documento.

Reforça-se, no conteúdo das matrizes, o caráter técnico-instrumental do trabalho docente - 0 que e como ensinar -, em detrimento do debate sobre os fins da educacãa, e do projeto histórico-social, abandonado pelas políticas neoliberais impostas nos últimos 10 anos. Entendemos que é este o debate necessário, que poderia trazer à tona e recuperar, no âmbito das políticas educacionais, as concepções mais avançadas sobre a formação dos educadores e seu papel na condução das transformações necessárias à escola, ao ensino, à educação e à sociedade.

O debate acumulado pela área nos últimos anos aponta para a formação de profissionais da educação/ educadores/ professores que possam lidar com os processos formativos de nossas crianças, jovens e adultos, em suas dimensões cognitiva, afetiva, da educação dos sentidos, da estética, corporal, artística, dos valores.

$\mathrm{O}$ trato dessas dimensões exige que a formação dos educadores para a construção de uma nova escola contemple ainda:

- a capacidade de romper com a fragmentação disciplinar e avançar para outras formas de trabalho com as crianças, na direção da unidade metodológica, do trabalho coletivo e interdisciplinar;

- as condições de auto-organização dos estudantes na gestão democrática da escola; a participação dos pais, da comunidade e dos movimentos sociais na vida da escola;

- a formação para a participação ativa na gestão democrática do projeto pedagógico da escola, na solidariedade com os colegas, no compromisso com a emancipação de nosso povo por meio da participação em suas entidades associativas científicas, acadêmicas e sindicais - , que possibilitem sua formação integral, multilateral.

Tais matrizes não tratam dessas dimensões e são, portanto, efetivamente, 0 que se propuseram desde a sua concepção vinculada ao exame de certificação: instrumentos de medida de competências e ava- 
liação do conhecimento de caráter técnico-instrumental dos professores, no complexo processo de regulação do trabalho docente - e, em consequiência, da formação inicial e continuada - que continua em curso, na esteira das políticas do governo anterior.

Sem este debate que a área da educação e da formação de professores vem fazendo há mais de uma década, e que 0 MEC e a SEIF têm ignorado, em todas as fases do processo, a aprovação das matrizes como elementos da política de formação torna-se inócua; elas servirão apenas, e tão-somente, efetivamente como matrizes sobre as quais se constituirão as questões da prova de um exame.

\section{II - A formação unitária dos educadores}

O campo da formação de professores está exigindo, há décadas, a definição de uma política global de formação e valorização do magistério, que contemple igualmente a formação inicial, condições de trabalho, salário e carreira e a formação continuada.

Mas está exigindo também firmeza e clareza quanto aos limites e às possibilidades das propostas altemativas na sociedade atual, e quanto à impossibilidade de desenvolvimento de uma formação de caráter emancipador no interior de um sistema profundamente desigual e excludente, nos marcos do capitalismo. Entender esses limites evita que possamos cair na armadilha das soluções fáceis, ágeis e de "menor custo" que caracterizam, via de regra, as iniciativas no âmbito da educação e particularmente da formação.

Travamos um debate no plano das idéias, das concepções, dos projetos históricos. Desse ponto de vista, uma perspectiva que desponta como promissora é a de retomar as construções históricas dos educadores para a formação do educador, recuperando os referenciais teóricos e metodológicos que orientaram e orientam a produção nesse campo, no que toca às condições de formação. Entre essas concepções está 0 conceito de base omum nacional, e a defesa do caráter sócio-histórico na formação dos educadores, centrada na concepção omnilateral das múltiplas dimensões da formação humana: cognitiva, ética, política, científica, cultural, lúdica e estética. Essas concepções vêm sendo construídas coletivamente no interior do movimento de reformulação dos cursos de formação dos profissionais da educação, e articulam a produção teórica na área juntamente com as práticas de formação de- 
senvolvidas nas escolas públicas, nas universidades, em seus cursos de licenciaturas e pedagogia.

A base comum nacional é concebida como forma de resistência aos processos de desqualificação e desvalorização do educador, mediante a imposição de uma perspectiva produtivista e tecnicista aos processos de formação. Esta concepção, que rompe com a idéia de currículo mínimo, referenciais, diretrizes e parâmetros, tão ao gosto das políticas educacionais atuais e de regulação do trabalho, de caráter neoliberal, supõe a defesa da autonomia universitária, no entendimento de que "a base comum nacional será desenvolvida em cada instituição de forma a respeitar as especificidades das várias instâncias formadoras" (ANFOPE, 1992, p. 14).

Pensar, portanto, uma política de formação de professores requer a superação das condições atuais de produção da formação do magistério, avançando para formas superiores na formação dos educadores, de profissionais da educação básica, considerando os princípios construídos historicamente pelo movimento.

Vivemos ainda na esteira das políticas do governo anterior, marcadas pela submissão às orientações dos organismos financiadores internacionais. Nosso desafio na atualidade é, ao mesmo tempo, exercer duramente a crítica às propostas que impedem que avancemos para novos patamares na formação e profissionalização dos profissionais da educação e indicar as alternativas construídas historicamente na perspectiva de superar as condições atuais: 0 rebaixamento da formação inicial pela liberalização, diversificação e ampliação indiscriminada dos cursos e das instituições formadoras, a regulação e o controle do exercício profissional (certificação e, quem sabe, a criação dos conselhos profissionais), e a implementação de uma política de formação continuada de caráter técnico-instrumental, centrada ex clusivamente nos conteúdos escolares e na avaliação e gestão, conforme pode ser identificado nas matrizes de referência para certificação aqui analisadas.

Este momento é propício para recuperarmos nossas concepções históricas de formação dos educadores, avançando para novas formas de organização e desenvolvimento dos espaços de formação de professores para um novo tempo e uma outra escola fundados em um projeto histórico social emancipador.

Recebido e aprovado em novembro de 2003. 


\section{Notas}

1. Cf. Art. 61 da LDB.

2. Cf. <www.mec.gov.br> - Audiência pública: formação de professores.

3. Cf. Banco Mundial, H igher E ducation: the lessons of experience (1994). As implicações desta organização do ensino superior foram exaustivamente denunciadas nos últimos anos tanto pelas entidades educacionais quanto por estudiosos da área (Cf. Aguiar, 1999; Catani \& D ourado, 2001) Ver especialmente revistas E ducação \& Sociedade n. 69 e 80.

4. O número de cursos normais superiores cresceu mais de $500 \%$ desde 2000 . Atualmente, há 668 cursos normais superiores. 0 censo realizado pelo ministério em 2001 indicou a existência de 306 cursos, 239 deles em instituições públicas e o restante em particulares. No ano 2000, havia apenas 110 cursos no país (0 E stado de S. Paulo, 31/ 7/ 2003

5. Cf. o site do MEC: <www.mec.gov.br> - Financiamento FIES.

6. Cf. o site <www.fazenda.org.br>.

7. Esta concepção está presente na configuração das universidades pedagógicas, existentes em vários países da América Latina como México, Venezuela e Cuba.

8. A exclusão do termo "ensino" da expressão "práticas de ensino", nos pareceres do cNE sobre formação de professores, retira definitivamente, o ensino do âmbito da educação, relegando-o ao campo das práticas em qualquer lugar do currículo.

9. Cf. o site do $\mathrm{CNE}$ : <www.mec.gov.br/ cne> - Consulta pública: formação de professores.

10. A primeira medida neste sentido vem com o Parecer $n^{0}$ 115/ 99 do CNE que regulamenta oS ISES, deslocando a formação de professores do âmbito acadêmico-científico das universidades e faculdades para o âmbito de instituições de caráter técnico-profissional.

11. Sobre comunidade e controle, ver artigo de Sally Power e Geof Whitty, "Mercados educacionais e a comunidade", em E ducação e Sociedade n. 84.

12. Cf. o site <www.grupos.com.br/ forum/ formacao-de-professores>, item Mensagens.

13. Cf. Informativo ACs, de 15/ 10/ 2003, disponível em: <www.mec.gov.br> - "MEC trabalha em várias frentes pela valorização dos professores".

14. O número de cursos de formação de professores, chamados de normal superior, cresceu mais de $500 \%$ desde 2000. Esse foi 0 ano em que o Ministério da Educação fixou que os professores - depois de 2007 - não poderiam mais ser contratados para trabalhar na rede pública sem apresentarem diploma de graduação. Atualmente, há 668 cursos de normal superior cadastrados no MEc, ou seja, que já têm autorização para funcionar. $\mathrm{O}$ censo realizado pelo ministério em 2001 mostrava que havia 306 cursos na época, 239 deles em instituições públicas e o restante em particulares. No ano 2000, havia apenas 110 cursos no país (0 E stado de S. Paulo, 31/ 7/ 2003).

15. Manifestação no início de junho, pela rede da ANFOPE, quando o Programa foi lançado.

16. Constata-se um processo de certificação não tão voluntário. Recentemente, o Fórum Nacional em Defesa da Escola Pública denunciou que o Formulário do Censo dos Profissionais do Magistério de Educação Básica, que o INEP/ MEC encaminhou aos profissionais da educação básica das escolas brasileiras, tem por finalidade "identificar o perfil do professor e constituir um cadastro para o Sistema Nacional de Certificação e Formação Continuada de Professores da Educação Básica" e traz ao seu final a exigência de que cada pro- 
fessor deverá marcar sim ou não e assinar sobre a seguinte afirmação: "Autorizo minha inscrição no sistema nacional de certificação e formação continuada de professores da educação básica", rompendo o compromisso firmado pela Secretaria de Educação Infantil e Ensino Fundamental ao final do Encontro Nacional (agosto 2003), de que tal processo seria adiado para $02^{\circ}$ semestre de 2004 .

17. Cf. o site da CNTE: <www.cnte.org.br> - Avaliar sim, certificar não.

\section{Referências bibliográficas}

AGUIAR, M.A. A formação do profissional da educação no contexto da reforma educacional brasileira. In: FERREIRA, N.S.C. (O rg.). Supervisão educacional para uma escola de qualidade. São Paulo: Cortez, 1999.

ANDRÉ, M. A pesquisa sobre formação de professores no Brasil: 19901998. In: CANDAU, V.M. (O rg.). E nsinar e aprender: sujeitos, saberes e pesquisa. Rio de Janeiro: D P\&A, 2000.

ARROYO, M.A. 0 fício de mestre: imagens e auto-imagens. Rio de Janeiro: Vozes, 2001.

BORGES, C.; TARDIF, M. Apresentação. D ossiê Os saberes do docente e sua formação. E ducação \& Sociedade, Campinas, v. 22, n. 74, p. 11-26, abr. 2001.

BANCO Mundial. Peligro y promesa: la educación superior en los países en desarrollo. Disponível em: <www.tfhenet/ report/ readreport.htm>. Acesso em: out. 2003

BRASIL. Lei n. 9394, de 20 de dezembro de 1996. Estabelece as diretrizes e bases da educação nacional. D iário 0 ficial da União. Brasília, DF, 23 dez. 1996.

BRASIL. Ministério da Educação e do Desporto. Secretaria da Educação Infantil e Fundamental. Matrizes de referência: anos iniciais do ensino fundamental. Brasília, DF: MEC/ SEIF, 2003.

BRASIL. Ministério da Educação e do Desporto. Secretaria da Educação Infantil e Fundamental. Toda criança aprendendo. Brasília, DF: MEC/ SEIF, 2003.

COD O, W. (Coord). E ducação: carinho e trabalho. Rio de Janeiro: Vozes, 1999. 
CONFEDERAÇÃO NACIONAL D OS TRABALHAD ORES EM ED UCAÇÃ O. Retrato da E soola I, II e III. Brasília, DF: CNTE, 20002002. D isponível em: <www.cnte.org.br> Acesso em: 2003.

DUARTE, N. Conhecimento tácito e conhecimento escolar na formação do professor (Por que Donald Schön não Entendeu Luria). E ducação \& Sociedade, Campinas, v. 24, n. 83, p. 601-626, agosto 2003.

ENCONTRO NACIONAL DA ANFOPE, 6., Belo Horizonte, 1992. D ocumento final. D isponível em: <www.lite.fae.unicamp.br/ grupos/ formac/ docanfope/ 6encontro.htm> Acesso em: nov. 2003.

ENCONTRO NACIONAL DA ANFOPE, 7., Niterói, 1994. D ocumento final. (mimeo.).

ENCONTRO NACIONAL DA ANFOPE, 8., Belo Horizonte, 1996. D ocumento final. Disponível em: <www.lite.fae.unicamp.br/ grupos/ formac/ docanfope/ capaencon8.htm> Acesso em: nov. 2003.

ENCONTRO NACIONAL DA ANFOPE, 9., Campinas, 1998. D 0cumento final. Disponível em: <www.lite.fae.unicamp.br/ grupos/ formac/ docanfope/ capa.html> A cesso em: nov. 2003.

ENCONTRO NACIONAL DA ANFOPE, 10., Brasília, DF, 2000. D ocumento final. D isponível em: <www.lite.fae.unicamp.br/ anfope/ > Acesso em: nov. 2003.

FORUM NACIONAL EM DEFESA DA ESCOLA PÚBLICA. Formar ou certificar?: muitas questões para reflexão. Brasília, DF, 2003. Disponível em: <www.Ipp -uerj.net/ olped/ noticias/ forum.certificar.doc> Acesso em: 2003

FREITAS, H.C.L. A reforma universitária no campo da formação dos profissionais da educação básica: as políticas educacionais e 0 movimento dos educadores. E ducação \& Sociedade, Campinas, v. 20, n. 68, dez. 1999.

FREITAS, H.C.L. Formação de Professores no Brasil: 10 anos de embate entre projetos de formação. E ducação \& Sociedade, Campinas, v. 23, n. 80, ago. 2002.

FREITAS, H.C.L. A formação dos profissionais da educação básica em nível superior: desafios para as universidades e faculdades/ centros 
de educação. In: Congresso Estadual Paulista sobre Formação de Educadores, 5., Águas de São Pedro, 1998. Formação do E ducador e avaliação educacional: formação inicial e contínua. São Paulo: UNeSP, 1999. v. 2, p. 103-127.

FREITAS, L.C. Neotecnicismo e formação do educador. In: Alves, N. (O rg.). Formação de professores: pensar e fazer. São Paulo: Cortez, 1992.

FREITAS, L.C. Cenário educacional: o legado dos anos 80 e a confusão dos anos 90. E agora? In: Simpósio do LAGE, 3., Jundiaí, 2000. A nais...

FRIG OTTO, G. A formação e a profissionalização do educador: novos desafios. In: G entili, P.; Silva, T.T. (O rg.). E scola S.A . Brasília, D F: CNTE, 1996.

ISAMBERT-JAMATI, V. O apelo à noção de competência na Revista L'Ò rientation Scolaire et Professionelle: da sua criação aos dias de hoje. In: Ropé, F.; TanguY, L. (O rg.). Saberes e competências: o uso de tais noções na escola e na empresa. Campinas: Papirus, 1997.

KUENZER, A.Z. A formação de educadores no contexto das mudanças do mundo do trabalho: novos desafios para as faculdades de educação. E ducação \& Sociedade, Campinas, v.19, n. 63, ago. 1998.

KUENZER, A.Z. Competência como práxis: os dilemas da relação entre teoria e prática na educação dos trabalhadores. Boletim Técnico do SEnA C, Rio de Janeiro, v. 20, n. 1, jan./ abr. 2003.

MACHAD O, L.R.S. A institucionalização da lógica das competências no Brasil. Proposicões, Campinas, v. 13, n. 1(37), p. 92-110, jan./ abr. 2002.

MANACO RDA, M.A. Marx y la pedagogia moderna. Barcelona: Tau, 1978.

MANFREDI, S.M. Trabalho, qualificação e competência profissional: das dimensões conceituais e políticas. E ducação \& Sociedade, Campinas, v. 19, n. 64, set. 1998.

MELLO, G.N. Formação inicial de professores para a educação básica: uma revisão radical.

(D ocumento principal; versão preliminar para discussão interna, out./ nov. 1999). (mimeo.). 
MIZALA, A.; ROMAG UERA, P. Sistemas de incentivos en educación y la ex periência del SNED en Chile. Santiago del Chile: Centro de Economia A plicada; Universidad de Chile, 1999. (Trabalho apresentado no Seminário Desenvolvimento Profissional de Professores, Brasília, DF, 1999). (mimeo).

MEC/ INEP/BID. 0 desempenho dos professores da A mérica Latina e Caribe: novas prioridades. Seminário realizado de 10 a 12 de julho 2002, em Brasília. (mimeo.).

MORDUCHOWICZ, A. Carreras, incentivos y estructuras salariales docentes. Buenos Aires: PREAL/ FlACSO, 2002. (Preal, n. 23).

OLIVEIRA, M.R.N.S. 20 Anos de endipe. In: EnCONTRO NACIONAL DE Didática e Prática de Ensino, 10., Rio de Janeiro, 2000. Rio de Janeiro: D P\&A, 2000.

POWER, S.; WHITTY, G. Mercados educacionais e a comunidade. E ducação \& Sociedade, Campinas, v. 24, n. 84, 2003.

RAMO S, M.N. A pedagogia das competências: autonomia ou adaptação? São Paulo: Cortez, 2001.

SAVIANI, D. Uma estratégia para a reformulação dos cursos de pedagogia e licenciatura: formar o especialista e o professor no educador. E $\mathrm{m}$ aberto, Brasília, D F, v. 1, n. 8, ago. 1982.

TANG UY, L. Racionalização pedagógica e legitimidade política. In: RoPÉ, F.; TAnguY, L. (O rg.). Saberes e competências: 0 uso de tais noções na escola e na empresa. Campinas: Papirus, 1997.

TARDIF, M.; RAYMOND, D. Saberes, tempo e aprendizagem do trabalho no magistério. E ducação \& Sociedade, Campinas, v. 21, n. 73, dez. 2000 .

TORRES, R.M. Melhorar a qualidade da educação básica? As estratégias do Banco Mundial. In: De Tommasi, L.; Warde, M.J.; Haddad, S. (O rg.). 0 Banco Mundial e as políticas educacionais. São Paulo: Cortez, 1996.

WHITTY, G. Controle do currículo e quase-mercados: a recente reforma educacional na Inglaterra e no País de Gales. In: SeminÁrio Internacional "Novas Políticas Educacionais: Críticas e Perspectivas", 2., São Paulo, 1996. São Paulo: PUC-SP, 1996. 